\title{
A MEDICINA SOCIAL E A QUESTÃO FEMININA *
}

\author{
SILVIA ALEXIM NUNES **
}

\section{A FORMULAÇÃO DE UM PROJETO}

É no século XIX que se constitui, no Brasil, uma medicina voltada para o controle do meio social e da população. Ela faz parte de uma tecnologia disciplinar surgida num determinado momento histórico com o objetivo de gerir a vida dos indivíduos, num projeto de normalização e controle do corpo social. ${ }^{1}$

Com a transferência do centro do poder português para a cidade do Rio de Janeiro e a organização de um novo aparelho estatal que provocou mudanças no conjunto da sociedade, tiveram início reformulações institucionais que possibilitaram a adequação da sociedade a uma nova ordem industrial e capitalista.

A organização social brasileira - estruturada desde a Colônia num sistema senhorial - se caracterizava, nesse momento, pela existência de uma população que

* Extraído de Medicina Social e Regulação do Corpo Feminino, tese de mestrado apresentada pela autora ao Instituto de Medicina Social da Universidade do Estado do Rio de Janeiro em 1982.

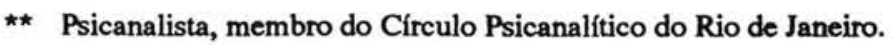

1. Ver FOUCAULT M., Vigiar e punir e "Política de saúde no século XVIII" in Microfísica do poder. 
ou estava diretamente ligada ao sistema produtivo ou era dele violentamente excluida, buscando formas marginais ou secundárias de subsistência. Na capital, o setor marginalizado foi mantido em tamanha indefinição social que experimentou com freqüência um processo desagregador. ${ }^{2} \mathrm{Na}$ medida em que essa massa social se tornava majoritária, com a desagregação gradual do sistema escravocrata senhorial,tornou-se necessário buscar novas formas de enquadramento social para ela. Inauguraram-se então diferentes procedimentos de contenção e disciplina, sem que isso tenha significado uma efetiva inserção na produção principal. ${ }^{3}$

Dessa forma, durante o século XIX constituíram-se lentamente mecanismos disciplinares, que se modificaram e expandiram na virada do Império para a República. Foi nesse contexto que se organizou uma medicina social no Brasil. ${ }^{4}$

No momento em que o crescimento desordenado da população e das atividades econômicas da cidade se tornou um problema político, criando um meio desorganizado que podia colocar em risco a própria sede do poder do Estado, surgiu nos discursos médicos a proposta de uma medicina social, voltada para atuar nos possíveis focos de transmissão de doenças. ${ }^{5}$ Cria-se uma medicina que em tudo intervém, que faz um esquadrinhamento total do meio social visando a um controle completo e permanente dos indivíduos, das instituições, de todos os setores sociais, regulando os elementos que possam determinar uma deterioração da saúde da população.

Já na primeira metade do século XIX um tipo de projeto médico tentou, através de um esquadrinhamento total do meio social, combater as condições de deterioração da saúde da população. Um projeto de intervenção sanitária na organização da cidade e dos indivíduos, cuja desordem era encarada como causa de doença e mortalidade. Debatia-se a necessidade de organizar hospitais, cemitérios, escolas, quartéis, bordéis, fábricas etc, considerados focos de transmissão de doenças. ${ }^{6}$ As moradias, o abastecimento de água, a alimentação - tudo se tornou objeto de uma postura preventivista dessa medicina que buscava diminuir o índice de enfermidades através de uma atuação junto às suas possíveis fontes de produção.

2. BIRMAN J., Formaçōes imaginárias e dispositivos da criminalidade. Relatório de pesquisa, mimeografado. IMS/UERJ. Rio de Janeiro, 1982.

3. Idem.

4. Idem.

5. Idem.

6. MACHADO R., Danação da norma. Graal, Rio de Janeiro, 1978. 
Nesse contexto, a higiene no interior da família adquire importância capital. Observa-se uma tentativa de intervenção nos costumes e hábitos familiares, visando à reorganização das relações entre pais e filhos, baseando o controle familiar no assessoramento da infância e no controle de mortalidade e natalidade. Os cuidados com as crianças devem iniciar-se desde o momento da concepção e prolongar-se por toda a infância. Os sistemas de áliança entre homens e mulheres passam a merecer atenção especial. O compromisso essencial do casal deve ser com os filhos, e as atividades domésticas, sexuais e sociais devem estar voltadas para a proteção da vida e da saúde das crianças. Nessa perspectiva, os papéis sociais de homens e mulheres são discutidos. A higiene inaugura um novo discurso sobre a condição feminina e masculina, visando à preservação da vida e da saúde. É preciso que homem e mulher se convertam às funções de pai e de mãe ${ }^{7}$.

A partir da preocupação com a criança e a família, a higiene começa a falar da mulher, que passa a receber atenção especial. Buscando diminuir os índices de mortalidade infantil, a medicina descobre a relação entre mãe e filho. Estabelecese um paralelo entre aleitamento mercenário e mortalidade, ponto de partida para que surja um projeto de intervenção médica que tentará regular toda a vida da mulher. Com argumentos biológicos, "científicos", os médicos tentam demonstrar que a mulher deve se situar no lar e na maternidade. Em relação à senhora, à mulher de família, a questão que se coloca é a de resgatá-la da submissão total ao pai para um novo lugar dentro da organização familiar. A medicina se volta para essa mulher - que era mantida reclusa, desvalorizada e sem qualquer tipo de autonomia - e passa a valorizá-la como esposa e mãe, como agente familiar do projeto médico de perpetuação e proteção da infância. No momento em que a preocupação básica é a preservação da natalidade e a contenção da mortalidade, tornar a mulher mais operante em suas funções maternas, delegando-lhe um novo estatuto dentro da família, é uma das estratégias do projeto médico que a define como um de seus objetos privilegiados. A partir de agora, ela deve ser acompanhada no seu dia-a-dia, submetida a uma vigilância médica necessária para torná-la capaz de desempenhar da melhor maneira possível a grande tarefa que lhe foi confiada. O estudo da condição feminina é considerado um dos pontos fundamentais da perspectiva higiênica da medicina.

"A mulher, pois, deve ser considerada de uma maneira minuciosa, atendendo ao sabido grau de importância de que se acha revestida."

7. FREIRE COSTA J., Ordem médica e norma familiar.Graal, Rio de Janeiro, 1983.

8. VALE L.V., Mulher e matrimônio medicamente considerados. Tese apresentada à Faculdade de Medicina do Rio do Janciro, 1847, p. 1. 
De início, pode-se notar que o discurso médico coloca o sexo feminino como aquele que a natureza fez mais adequado aos cuidados com a infância. Torna-se, assim, científico o velho mito, segundo o qual a mulher teria sido feita para o lar e o homem, para o trabalho. Com isso, se relativiza o poder total do pai sobre a criança, que pode se tornar inadequado ao bom desenvolvimento desta. Os médicos, reconhecendo a utilidade da mulher enquanto agente dos cuidados com as crianças, procuram estabelecer uma aliança com a mãe através de uma valorização de seu estatuto dentro da família?.

Com o argumento da natureza, tenta-se justificar de forma incontestável esse tipo de colocação e, com isso, impedir que se possa refutar o novo lugar dado à mulher na estrutura familiar. Não se trata, no entanto, de colocá-la em posição livre de dominação, mas sim de submeter também o pai a uma nova ordem médica. A mulher não se torna liberada por esse tipo de proposição da medicina, mas é recolocada em uma nova forma de relação de dominação, através da transferência de uma tutela paterna para uma tutela higiênica. O que se observa nos textos médicos não é o surgimento de um saber que a coloque como alguém capaz de se igualar socialmente ao homem, mas, ao contrário, a organização de um discurso que justifica positivamente a idéia de inferioridade feminina. Dessa forma, a medicina agora fala pela mulher e diz como ela é e de que forma ela deve viver.

Segundo os médicos, tudo na organização biológica da mulher está voltado para a procriação, e é a partir desse fato que a natureza a torna inferior ao homem. Para se tornar o depositário de um feto, a mulher é alguém cujos demais órgãos não merecem grande atenção da natureza, que aperfeiçoa apenas o seu aparelho reprodutor. Em sua constituição física e moral, tudo o mais é frágil, pouco desenvolvido, sempre relegado a segundo plano.

"Toda a constituição moral da mulher", diz Virey, "resulta da fraqueza inata de seus órgãos; tudoé subordinado a esse principio peloqual a natureza quis tornar a mulher inferior ao homem." 10

No entanto, apesar de tratar a mulher como um ser inferior, os discursos médicos não dão, nesse momento, nenhum caráter patológico ou anômalo a essa

9. Jacques Donzelot mostra a importância que teve a aliança entre a medicina e a mulher para a reorganização do modelo familiar na França. DONZELOT J., A policia das familias. Graal, Rio de Janeiro, 1980.

10. MONTEIRO DE BARROS J.F., Considerações gerais sobre a mulher e sua diferença do homem e sobre o regime da mulher durante a prenhez. Tese apresentada à Faculdade de Modicina du Rio de Janeiro, 1845, p. 7. 
inferioridade. Ao contrário, essa determinação biológica é considerada uma artimanha da natureza, para possibilitar à mulher cumprir convenientemente suas funções, já que esta sua característica mais frágil é que lhe permitiria desempenhar o papel de mãe. Nesse sentido, sua limitação não pode ser considerada um defeito, e sim uma virtude que a torna apta a cuidar de um ser igualmente frágil.

"A fraqueza e a sensibilidade são as qualidades dominantes e distintas da mulher(...) essa organização era, como já dissemos, indispensável ao sexo ao qual a natureza devia confiar o depósito da espécie humana, ainda fraco e impotente." "I

Para comprovar a inferioridade feminina como um fato constitucional, determinado biologicamente, a medicina amplia a idéia da diferença anatômica para o psiquismo, postulando uma diferença mental.

“... desde a mais tenra infância o esqueleto de um sexo é bem diferente do outro, $\mathrm{e}$ essa diferença existindo igualmente na maior parte dos órgãos, não poderia, por conseqüente, deixar de achar-se no caráter moral que é sempre influenciado pela conformação física". 12

A partir dessa suposta diferença moral, a medicina postula uma tendência a adotar comportamentos e formas de vida diversas daquelas comuns ao homem. $\dot{E}$ isso que faz com que,dentro da sociedade, a mulher não tenha responsabilidades, se dedicando a passatempos e a ocupações mais delicadas e mais frivolas, condizentes com as caracteristicas de seu sexo. Como a medicina necessita fixar a mulher no papel materno, utilizando-se para isso de uma perspectiva positiva que a enquadre nesse modelo, qualquer tentativa de usar outro tipo de abordagem para explicar a inferioridade social feminina é vivamente atacada pelos higienistas.

"Muitos filósofos fazendo abstração da organização primitiva, têm observado sua fraqueza física como resultado do gênero de vida que a sociedade lhe impöe, e sua inferioridade nas ciências depende unicamente de sua má educação; mas nós pensamos de outra maneira e julgamos que nosso estado social deve ser considerado aqui antes como efeito do que como causa."13

11. MONTEIRO DE BARROS J.F., Considerações gerais sobre a mulher e sua diferença do homem e sobre o regime da mulher durante a prenhez. Tese apresentada à Faculdade de Medicina do Rio de Janeiro, 1845, p.9.

12. PEREIRA M.J., Generalidades sobre o físico e o moral da mulher. Tese apresentada à Faculdade de Medicina do Rio de Janeiro, 1852, p. 3.

13. MONTEIRO DE BARROS J.F., op.cit.p.8. 
É clara a tentativa médica de dar uma justificativa positiva para a situação da mulher na sociedade; todas as teses tentam tornar esse argumento irrefutável, o que demonstra uma clara perspectiva de manter a mulher num determinadolugar social. Suas características físicas são minuciosamente estudadas e consideradas como fatores determinantes de sua capacidade moral e intelectual; as mulheres são, por exemplo, consideradas mais sensiveis, impressionáveis, volúveis, inconstantes, extremosas, graciosas, pois seu sistema nervoso possui maior quantidade de tecido celular; ou então são tidas como seres nascidos para amar e ser amados, por causa da pequena estatura e das formas arredondadas e lisas. Portanto, discutindo as diferenças biológicas entre homens e mulheres, tratando estas últimas como seres inferiores, a medicina as reduz à condição de reprodutoras, negando a elas, com um discurso que as torna inaptas a outras funções, qualquer outro tipo de atividade na familia ou na sociedade de um modo geral.

"Segue-se portanto que as ciências, as artes, as invenções, não devem merecer muito a atenção do belo $\operatorname{sexo}(. .$.$) uma incompatibilidade manifesta existe entre a$ abstração matemática e as distrações pueris, entre a volubilidade de seus pensamentos e a estabilidade de uma questão fisica." ${ }^{14}$

Ora, considerada tão importante diante das necessidades da vida, a mulher precisa de algum tipo de apoio, para que possa manter-se e sobreviver; e, para auxiliá-la nessa tarefa, nada mais adequado do que a vida em familia e o convívio com um marido. A medicina reforça então outro axioma em relação à condição feminina, segundo o qual o matrimômio lhe é útil e necessário. O casamento é considerado fundamental para a mulher, não por razões sociais, afetivas ou sexuais, mas por uma necessidade biológica.

"Daí vem, segundo creio, a necessidade de admitir como verdade fixa e irrecusável que a mulher é dominada pela precisão de união e o homem pelo desejo do gozo." 15

A questão do casamento abre espaço para que a medicina dê também fundamento científico para outra ideologia sobre a mulher: a sexualidade seria, para ela, menos importante do que para o homem; o desejo feminino se transforma em uma necessidade conjugal.

14. PEREIRA M. J., op. cit., p. 9.

15. VIANNA A.F., Considerações higiênicas e médico-legais sobre o casamento relativamente à mulher. Tese apresentada à Faculdade de Medicina do Rio de Janeiro, 1842, p.3. 
Para reforçar a idéia de que o casamento deve ser considerado uma necessidade decorrente de fragilidade constitucional da mulher, minimizando a questão sexual, os médicos dão como exemplo a situação das prostitutas que, apesar de possuírem vida sexual ativa, apresentam muitas vezes doenças tipificadas como "monomanias amorosas". O mesmo ocorre com mulheres que têm filhos fora da união legal ou ainda solteiras. A existência desse tipo de monomania prova que a satisfação sexual não é considerada importante na vida feminina e sim a satisfação conjugal. Ora, se a falta do casamento é um fator provável de adoecimento, seu incentivo passa a ser encarado como uma medida profilática.

-Tendo pois a moça chegado à idade núbil, quando ela for dotada de um temperamento ardente e apaixonado, o matrimônio deve ser proposto e favorecido do modo que for possivel."16

Construindo um discurso sobre a condição feminina, no qual a mulher é considerada voltada para a maternidade, a medicina, ao mesmo tempo em que delega à mulher uma nova importância dentro do modelo familiar, a reduz ao papel de esposa e mãe, atribuindo a essa perspectiva um aspecto científico.

No entanto, a partir da virada da década de 1870 a preocupação médica sofre uma importante modificação. Apesar de persistir a perspectiva da higiene pública, a ênfase do projeto médico volta-se principalmente para uma perspectiva de formação de um novo tipo de indivíduo, para o aprimoramento da população, para a melhoria da raça. Não são atacadas apenas as condições de produção de doenças, mas se passa a promover a saúde, tentando produzir indivíduos física e moralmente adequados a um determinado projeto social. Não se trata mais, apenas, de proteger o Estado contra os problemas colocados pelas doenças, mas, sobretudo, de exterminá-las pela promoção de um novo corpo social. Assim como se pode programar os animais para objetivos determinados, a medicina vai se propor a programar também os indivíduos.

"Nós vemos a cada passo homens cuidando dos animais para determinados fins; uns são destinados à caça, outros às corridas, outros a fornecerem alimentação de sua carne e outros enfim para trabalhos especiais, por meio de certo regime, exercício, moradia e de todas as circunstâncias que uma higiene estudada pode determinar. Por que também não estudaremos um meio de aperfeiçoar a nossa raça por meio de uma higiene própria? Só a higiene fará de uma criança débil

16. VIANNA A.F., Considerações higiênicas e médico-legais sobre o casamento relativamente a mulher. Tese apresentada à Faculdade de Medicina do Rio de Janeiro, 1842, p. 8. 
um homem robusto, corrigindo as más disposições que não encontram remédio na medicina." 17

Produzir um novo tipo de indivíduo, mais adequado a um determinado projeto político de organização da sociedade, é nesse momento o objetivo fundamental. O que se propõe não é apenas uma preservação populacional, mas uma intervenção direta sobre a formação das individualidades, um controle que deve operar diretamente sobre seus corpos para adestrá-los e discipliná-los, a fim de obter simultaneamente sua docilização e o aumento de sua produtividade. Um projeto médico que faz parte de uma tecnologia de gestão populacional, calcada numa perspectiva de disciplinarização e normalização da população.

Nesse momento, a instituição psiquiátrica ganha um lugar de relevo nos discursos médicos. Preocupando-se basicamente com o aspecto da formação moral dos indivíduos, o saber psiquiátrico se expande, voltando-se para uma perspectiva específica de higiene moral, complementando uma tarefa que a higiene pública inaugurou de forma bastante eficiente. A psiquiatria se constitui, enquanto projeto social, em uma nova modalidade de higiene, que se passa no nivel dos sentimentos, das emoções e das paixões ${ }^{18}$.

Nessa perspectiva, ganha vulto a noção psiquiátrica de degeneração psíquica, uma desordem nos centros nervosos capaz de produzir tais perturbações no pensamento e nos sentimentos que tornaria os indivíduos pouco aptos à vida.

"O degenerado é todo aquele que, vitorioso ou vencido na luta pela existência, por defeitos hereditários ou por lesões adquiridas do caráter ou por funcionamento atávico, psíquico, fica improdutivo ou nocivo à sociedade." 19

A noção de degeneração, trazida pela psiquiatria, amplia consideravelmente a estratégia médica. O risco de que alguém sucumba aos aspectos degenerativos que possui, justifica um maior aprofundamento da intervenção médica na vida dos indivíduos. A partir do estudo de problemas como a alienação mental e a criminalidade, a psiquiatria diz que na base desses quadros existe uma má formação, uma deficiência física e mental que explica esses comportamentos. Uma constituição degenerada liga louco e criminoso. Esse aspecto constitucional

17. SILVA A.S., Higiene da primeira infância. Tese apresentada à Faculdade de Medicina do Rio de Janeiro, 1882 , p. 8.

18. Ver BIRMAN J., A psiquiatria como discurso da moralidade. Graal, Rio de Janeiro, 1979.

19. OLIVEIRA L., Da degeneração psíquica. Tese apresentada à Faculdade de Medicina do Rio de Janeiro, 1895, p. 1. 
anômalo ganha relevância nos discursos médicos de então. O degenerado é alguém que sucumbiu a um processo civilizatório deficiente, permanecendo num estágio anterior, apresentando ainda caracteres selvagens, constituindo-se numa ameaça ao desenvolvimento social, não só pelo fato de que seus atos podem prejudicar outros indivíduos, como também por se tratar de um portador de características passiveis de transmissão hereditária, o que pode levar a um processo de degradação social. Para prevenir a expansão desse tipo de anomalia e corrigir as más formações, a higiene mental se torna um dos pilares da estratégia do projeto médico de higiene social.

Apoiada nessas teorias, a medicina cria um novo tipo de patologia que abre espaço para que se trate todo e qualquer desvio de comportamento como sinal de degeneração psíquica. Criam-se assim novos objetos de intervenção, na tentativa de circunscrever os efeitos nocivos que os portadores dessas características podem trazer à estratégia de aperfeiçoamento físico e moral do povo. Criminosos, prostitutas, alienados, histéricos, negros, escravos, desviantes sexuais, infanticidas são exemplos de indivíduos que a medicina trata como produtos degenerados da população. É este o ponto de partida para uma tentativa de intervenção em todo e qualquer comportamento que não corresponda aos ideais higiênicos.

Nesse contexto, a importância da família assume novas proporções. Lugar onde o indivíduo se constitui, a família torna-se fundamental, como possível foco de transmissão de estigmas degenerativos e, ao mesmo tempo, local privilegiado para corrigir toda e qualquer anomalia. A questão da infância, as relações familiares, as formas de aliança, os papéis sexuais, os lugares sociais, tudo isso passa a ser pensado de acordo com essa nova perspectiva. A preocupação com a criança não está mais baseada no binômio nascimento-morte: trata-se agora de protegê-la ao máximo das condições que possam feri-la ou depravá-la. A formação de uma infância física e moralmente sadia, capaz de responder às necessidades sociais, é o principal tema dos debates médicos e o fio condutor de um novo projeto de higiene infantil. Com o objetivo de preparar as crianças para um futuro livre de aspectos degenerativos e, conseqüentemente, para alcançar um desenvolvimento adequado, a higiene social propõe regras minuciosas, cuidados constantes, modificações nos hábitos familiares e mudanças no sistema educacional com vistas a garantir uma boa formação física e moral para cada futuro cidadão.

"Preparar o coração e o espírito de modo a fazer do indivíduo um ser moral é o fim da educação que, iniciada na familia, completa-se na Pátria. ${ }^{20}$

20. SIMÕES A.A.,Higiene da primeira infância. Tese apresentada à Faculdade de Medicina do Rio de Janeiro, 1882, p. 37. 
A questão da educação moral é, portanto, um dos pontos chaves dos discursos médicos sobre os cuidados com a infância.

Para atingir esses objetivos, muitos costumes familiares são atacados e outros, incentivados. Pai e mãe devem educar as crianças visando aperfeiçoar suas potencialidades e conter seus instintos anti-sociais. Desde a mais tenra infância, a educação deve basear-se nos princípios da moral higiênica; os hábitos devem ser ensinados em cada momento, para que fiquem desde cedo internalizados; de uma maneira geral o processo educativo deve constituir-se em uma forma de disciplina dos desejos e das paixões. Outro tema que ganha nova importância nesse instante é o casamento. Os sistemas de alianças também devem estar de acordo com essa nova perspectiva de aperfeiçoamento físico e moral dos indivíduos. Baseados nos princípios da degeneração e hereditariedade, os médicos justificam a necessidade de intervir nas uniões conjugais, para promover a regeneração do caráter nacional, evitando a proliferação de taras e anomalias e controlando possíveis desvios. Mas não é apenas para proteger as crianças que esses princípios devem ser observados, pois a união conjugal deve ter por fim contribuir também para o aprimoramento do casal e a atenuação de suas imperfeiçōes; homens e mulheres, com suas características diversas e complementares, devem se auxiliar, proteger e aperfeiçoar mutuamente. O casamento, quando se realiza sob a égide dos preceitos da higiene, traz conseqüências positivas para toda a sociedade.

“...em relação ao individuo, à espécie e à sociedade o casamento dominado pelos preceitos da sã higiene preenche seus benéficos resultados". ${ }^{21}$

Os casamentos baseados em interesses familiares são cada vez mais atacados por não levarem em conta essa perspectiva profilática. Observa-se uma tentativa mais contundente de colocar a ordem da família sob o controle médico, à medida que se propõe que nenhuma decisão dessa espécie seja tomada sem apreciação médica. Critica-se, por exemplo, o hábito de os indivíduos se casarem dentro de uma mesma família, sem levar em conta a opinião médica, como um dos fatores de proliferação de taras degenerativas.

"Para a infelicidade da sociedade, certos princípios de família e o fato de os médicos não serem consultados a respeito fazem com que uma diátese em uma familia, longe

21. LOPES DE FIGUEIREDO J.A.,"Dos casamentos do ponto de vista higiênico", in Dos diagnósticos dos tumores dos testículos. Tese apresentada à Faculdade de Medicina do Rio de Janeiro, 1880 , p. 76. 
de se extinguir, se acentue cada vez mais em conseqüência dos casamentos entre indivíduos da mesma família."22

Para que se obtenha uma alteração nos costumes familiares considerados perniciosos ao projeto de regeneração social, aparecem propostas de modificação na legislação, de forma que práticas como casamentos com grandes diferenças de idade, casamentos na idade precoce ou avançada e outros casos, nos quais a proliferação de estigmas degenerativos possa levar a problemas mais graves, sejam impedidas através de medidas que proíbam sua recorrência.

A medicina enfatiza a necessidade de se estabelecerem laços conjugais calcados nos princípios da higiene. $O$ casamento, nessa perspectiva, é considerado o pilar de uma organização social voltada para a preservação populacional. Qualquer outro tipo de união e formas diversas de vida que fujam a esse modelo passam a ser muito criticados como atos contra a natureza humana, como acontece com o celibato e a poligamia, que passam a ser vistos como formas de vida que podem levar ao enfraquecimento físico e moral dos individuos.

No entanto, o casamento não é recomendado aleatoriamente, sob quaisquer circunstâncias; no caso dos indivíduos portadores de doenças e de aspectos constitucionais degenerados, ele deve ser contra-indicado.

"Tem-se visto, por herança, passar de pais a filhos não só os defeitos inatos como os adquiridos(...) As diáteses de todo o gênero podendo passar de pais a filhos contra-indicam o casamento." ${ }^{23}$

No cerne dessa questão encontra-se a necessidade de impedir os casamentos que possam representar uma ameaça ao projeto de regeneração social. Como medida preventiva, os médicos propõe a instituição de exames pré-nupciais obrigatórios. Esse tipo de discurso, que se estende por toda a Primeira República, desembocar na década de 1920 num projeto claramente eugênico. ${ }^{24}$ Nesse contexto, a questão feminina se coloca de outra forma. A preocupação com a mulher se exacerba e os trabalhos voltados para seus problemas se modificam.

Com a desestruturação do sistema senhorial, observa-se, de um lado, o crescimento de uma parcela da população feminina que se situa à margem do binômio senhor-escravo e que possui um tipo de vida não tão restrito como se poderia espe-

22. FREITAS DRUMOND A.M., "Dos casamentos sob o ponto de vista higiênico, in Phtisica pulmonar. Tese apresentada à Faculdade de Medicina do Rio de Janeiro, 1880, p. 225.

23. LOPES DE FIGUEIREDO, op. cit., p.7.

24. Ver FREIRE COSTA J., História da Psiquiatria no Brasil. Documentário, Rio de Janeiro, 1976. 
rar. Mulheres saídas de camadas mais baixas da população, escravas libertas, mestiças e brancas pobres subsistem com certa autonomia, chegando mesmo a formar um contingente nada desprezível da população economicante ativa. ${ }^{25}$ Por outro lado, nas camadas dominantes, a reclusão feminina parece se relativizar, e apesar de não existir uma modificação significativa em sua posição social, o processo de urbanização e o ambiente da cidade propiciavam às mulheres um maior contato social. Começam então a ser vistas em outros locais, além de igrejas e festividades, a possuir alguma liberdade de movimento, chegando mesmo a existir uma ou outra que se torna emancipada econômica e intelectualmente..$^{26} \mathrm{O}$ século XIX trouxe, portanto, gradativamente, uma série de modificações na vida das mulheres das cidades, existindo mesmo um nascente movimento feminista nas últimas décadas. ${ }^{27}$

Toda essa mudança no comportamento feminino, toda a tendência a sair da reclusão do lar, cria mais um obstáculo para a estratégia global da medicina. O tipo de vida levado pelas mulheres, as suas atividades sociais e produtivas, se tornam alvos de críticas e das preocupações médicas. Dentro da estratégia de regeneração social, o aparecimento de um tipo de mulher mais voltado para o mundo externo à casa é um problema novo, já que as mulheres aparecem com novas formas de vida, podendo tornar-se uma grande ameaça ao ideal de esposa e mãe. Nesse momento, os discursos médicos aprofundam os estudos sobre a natureza feminina, transformando em anomalia as peculiaridades desse sexo, numa tentativa de circunscrevê-lo a um determinado padrão. Os textos médicos mudam de tom e constroem um novo tipo de saber sobre a mulher, tentando demonstrar que, se por um lado ela está voltada para o amor, é também capaz de se tornar autora de grandes atos anti-sociais. $\mathrm{O}$ sexo feminino não será mais, a partir de agora, o lugar das virtudes e dos bons sentimentos, mas também, e principalmente, um lugar onde maus instintos podem se desenvolver. Tomando como base o estudo de fenômenos sociais como aborto, infanticídio, prostituição e loucura, detectam-se sinais de uma monstruosidade peculiar a toda e qualquer mulher. Vemos então intensificar-se uma corrente segundo a qual o sexo feminino possui uma base degenerada, que predispõe ao aparecimento de comportamentos anti-sociais, por ter sido submetido a um processo civilizatório inadequado, que o tornou menos desenvolvido.

25. "Era bastante alta a percentagem de mulheres que participavam das atividades econômicas em 1872. Mesmo excluindo-se as que se ocupavam dos serviços domésticos, as mulheres representavam $37,4 \%$ da força de trabalho efetiva total da nação." SAFFIOTTI I.B.H., $A$ mulher na sociedade de classes: mito e realidade. Vozes, Petrópolis, 1979, p. 239.

26. HAHNER J.E., A mulher no Brasil. Civilização Brasileira, Rio de Janeiro, 1978.

27. Idem, p. 79. 
"Foram as contingências da vida civilizada erradamente orientada que fizeram pela longa sedimentação dos anos a inferioridade física da mulher. ${ }^{28}$

Não estariam, portanto, na dependência apenas da biologia as deficiências da mulher, mas também de um tipo de civilização que não llhe deu maiores oportunidades de ter um bom desenvolvimento. Comparando-a com o homem, utilizando-se de estudos antropológicos, a medicina vai reafirmar a idéia de inferioridade feminina, dando-lhe agora novas cores, já que transforma a diferença entre os sexos em sinal de anomalia da mulher. Essa inferioridade deixa então de ser considerada sinal de uma fragilidade compatível com as funções do sexoe passa a ser pensada como um sinal de que a mulher possui um tipo primitivo, degenerado, anti-social, mais aproximado do selvagem e do criminoso.

"A investigação antropológica demonstra que nas raças mais adiantadas os lobos frontais são mais desenvolvidos(...), o crânio feminino aproxima-se menos do que se pode chamar o tipo frontal do que o masculino(...) na mulher os lobos lateral e posterior do crânio têm maior superfície do que no homem. Era esse o tipo craniano do criminoso." 29

Comparando a mulher ao homem pré-histórico, dando ao sexo feminino um lugar de degenerado, os médicos combatem violentamente qualquer outro tipo de abordagem que veja a mulher sob um prisma diferente. Criticam, por exemplo, a idéia veiculada por romances e poemas, de que as mulheres seriam mais sensíveis que o homem; propõe-se então que, na verdade, a mulher possui uma menor capacidade de dominar seus sentimentos.

É essa idéia de uma constituição feminina de base degenerada que vai nortear todo o projeto médico de intervenção junto à mulher, a partir do final do século. Esse tipo de visão possui uma grande força e aspectos vantajosos para a estratégia médica; ao mesmo tempo em que ajuda fixá-la num determinado papel, justifica (já que torna o sexo feminino uma ameaça ao projeto de regeneração social) um maior controle da camada feminina da população, numa tentativa mais contundente de evitar desvios e ampliar suas potencialidades.

\section{II - O PERFIL FEMININO E AS FORMAS DE DESVIO}

Vemos surgir, portanto, um discurso médico que coloca a mulher como um ser pleno de características degeneradas, virtualmente perigoso para o projeto de

28. SPARANO L., O sexo em patologia (a questão feminia). Tese apresentada à Faculdade de Medicina do Rio de Janeiro, 1916, p. 20.

29. Idem. 
aperfeiçoamento da espécie. Tal discurso pretende circunscrever os comportamentos femininos 'anti-sociais' dentro de limites inócuos, de modo a produzir um rendimento ótimo de suas funções dentro da sociedade.

Dada a importância atribuída ao comprometimento da mulher, a medicina, a partir do momento em que começa a sentir ameaçado o seu projeto de regeneração popular, aprofunda o estudo das características femininas, passando a pensar todos os seus aspectos de forma minuciosa e demonstrando a cada passo a primitividade de sua constituição.

Partindo do pressuposto de que o organismo da mulher apresenta particularidades pouco desenvolvidas, a medicina a classifica como raça inferior.

-A mulher ainda observa hoje no estado fisiológico os vestígios de uma espécie que deu origem à raça humana." ${ }^{30}$

Dessa forma, tenta-se demonstrar positivamente que todo o seu organismo possui características inferiores. Não apenas como no primeiro momento, quando seu físico mais arredondado e frágil, voltado para a procriação, constituía o ponto de apoio para um discurso de inferiorização e fragilização anatômica compativel com a matemidade. A diferença agora se dá em outro nível; o que se coloca é a questão de que essa inferioridade está ligada a um aspecto de não-evolução da mente, dos pensamentos e sentimentos. Assim, o cérebro possui volume, peso e forma inferiores, os gânglios e a medula são mais desenvolvidos, como em estágios infantis, e a mentalidade não se desenvolve adequadamente. A mulher é, portanto, o indivíduo adulto que não cresceu.

"O cérebro da mulher liga-se em relação ao passado ao cérebro do selvagem, em relação ao presente ao cérebro da criança. Assim se demonstra que a fraqueza do sexo feminino não reside no físico(...) A diferença está na mentalidade. O homem primitivo, a criança de hoje e a mulher, feitas certas restrições relativas ao meio, representam a infância da humanidade." ${ }^{31}$

Apesar de essa ideologia médica considerar que o problema da mulher está ligado à sua história e ao desenvolvimento da civilização, sua inferioridade se torna aquisição orgânica, já que, de acordo com as teorias da época, esses aspectos, quando se constituem, passam a ser transmitidos hereditariamente. Tendo experimentado uma evolução deficiente e sofrido uma estagnação constitucional, a

30. LIVIO DE CASTRO T., A mulher e a sociogenia. Guanabara, Rio de Janeiro, 1894, p. 7.

21 Idem, p. 95. 
mulher ganha da medicina um status infantil, tornando-se alguém que não está apto a cuidar de si mesmo, que não alcançou a maioridade.

"Foi isso que se deu com a mulher. O meio em que se exerceu sua atividade mental foi sempre idêntico ao da espécie no seu período primitivo ou infantil. Ela não teve incentivos para chegar à maioridade e conservou-se até hoje criança. ${ }^{-32}$

A partir dessa perspectiva a medicina diz que a mulher não tem condições de gerir a própria vida. Então se observa um movimento vigoroso no sentido de fixála numa determinada posição social. Se, no primeiro momento, para que a medicina pudesse dotar a mulher de algum poder dentro da família, foi necessário considerála a mais adequada para a guarda dos filhos, tendo para isso que the delegar um novo estatuto que implicava alguma autoridade, o movimento agora parece inverso. Suas características não são valorizadas. Ao contrário, são desqualificadas a um tal ponto que, de acordo com essa visão, quase nada parece demonstrar que a mulher seja capaz de exercer alguma função social. Não é um discurso que procura dar-lhe alguma legitimação: ao contrário, pretende torná-la inapta ao exercício de qualquer tipo de poder, a um tal ponto que, em vez de tratá-la como alguém com potencialidades, a torna impotente e incapaz, com tendência a ser dominada.

"Uma escravidão de muitos mil anos é mais que bastante para fazer do servilismo uma tendência orgânica inata, e foi essa a escravidão da mulher. ${ }^{33}$

Dessa forma, a mulher, possuidora de uma estrutura tão precária, torna-se no pensamento médico um grande perigo para a evolução da espécie, já que participa mais do que o pai na constituição dos filhos e de suas predisposições mórbidas. Ao mesmo tempo, essa constituição doentia que determina a existência de uma série de desvios sociais femininos que podem ser explicados fisiologicamente. Tenta-se demonstrar que se algumas mulheres não respondem adequadamente aos seus papéis tradicionais é por causa dessa organização física e mental inferior. A falta de zelo com os filhos e a familia, a não-amamentação das crianças, as diversas formas de loucura, o aborto e o infanticídio, o adultério, a prostituição, a vida desregrada, são demonstrações de que a mulher, quando pouco cuidada, pode sucumbir à sua fragilidade. Quando, por exemplo, a medicina estuda as diferentes formas de alienação mental e o sem-número de conseqüências que este estado pode trazer para a organização social, já que se constitui em mais uma fonte de

32. Idem, p. 144.

33. Idem, p. 114. 
desagregação, a questão feminina tem um lugar especial. Ressaltando algumas formas de doença mental típicas das mulheres, os discursos médicos atribuem ao sexo feminino maior predisposição para a loucura em função de sua constituição física mais sujeita a abalos morais.

"A hereditariedade da loucura, porém, afeta mais os indivíduos do sexo feminino(...) este fato é de fácil explicação em vista da idiossincrasia moral da mulher que a expõe mais do que o homem às diversas lesões nervosas." ${ }^{34}$

Fazendo o mesmo tipo de raciocínio na questão do aleitamento infantil, a medicina mostra que a mãe que não amamenta o seu filho é também alguém que sucumbe a seus aspectos degenerados, tornando-se passível de ser tratada como uma criminosa, voltada apenas para seus desejos e caprichos.

"A mãe que não aleita o seu filho, é como diz o doutor Kuborn, criminosa ou infeliz. A primeira é aquela que encara os deveres da maternidade como um fardo muito pesado que lhe embaraça em seus divertimentos, é a jovem e elegante senhora que tem medo de prejudicar a sua beleza e a elegância do seu talho..." ${ }^{35}$

Nessa perspectiva, três figuras femininas aparecem como modelos de mulher que, por seus aspectos degenerados, se tornam francamente anti-sociais. Não constituem, contudo, como no primeiro momento, tipos especiais femininos, mas demonstram a existência de uma base degenerada comum a todas as mulheres. São elas a infanticida, a louca e a prostituta.

\section{1 - A mulher criminosa}

Os trabalhos médicos que mostram de maneira mais contundente a que ponto de selvageria pode chegar uma mulher e que grau de periculosidade existe em cada elemento do sexo feminino são os que discutem o aborto e o infanticídio. Nessa época, tais temas são tratados de forma bastante diferente da que aparece no início do século, quando não se observa um interesse maior em dotar a mulher criminosa de características perversas; ao contrário, fatores sociais, doenças mentais e tentativa de preservação da honra familiar são considerados atenuantes para o crime, e, como tal, de maneira geral reconhecidos nos textos médicos. A questão

34. RODRIGUES OLIVEIRA O.S., Loucura puerperal. Tese apresentada à Faculdade de Medicina do Rio de Janeiro, 1882, p.10.

35. MARTINS J.F., Higiene da primeira infancia. Tese apresentada à Faculdade de Medicina do Rio de Janciro, 1882 , p. 9. 
primordial, no primeiro momento, é a preocupação com a sobrevivência das crianças. Esses atentados aparecem colocados entre os fatores que contribuiriam para um aumento da mortalidade infantil. A mulher autora de um ato violento não é ainda especialmente considerada numa perspectiva patologizante.

A partir da década de 1870 , as discussões sobre esses crimes se modificam inteiramente. Os discursos se tornam muito mais contundentes, e o julgamento médico contribui para uma classificação mais rigorosa e a adoção de penalidades mais violentas. Considera-se, por exemplo, o infanticídio muito mais grave do que qualquer outro tipo de homicídio, porque se tem certeza da inocência da vítima e porque se trata de um ente incapaz da menor resistência. Outro movimento bastante claro é uma tentativa de reforçar a idéia de que esses delitos atentam contra a ordem pública. Tornam-se mais incisivos os ataques contra o costume das familias de procederem a esses atos e mais veementes os pedidos de uma legislação mais rígida. A defesa da honra deixa de ser circunstância atenuante, como acontecia no início do século, e passa a ser considerada agravante. Mas a grande novidade que aparece nos textos no final do século é o tratamento dado às mulheres que cometem esses crimes. Antes consideradas umas pobres-coitadas que, para resguardar sua honra e a de sua família, ou para não trazer ao mundo filhos que não teriam condições de cuidar, chegavam a matá-los, tornam-se agora seres monstruosos, perversos, capazes das maiores atrocidades.

"Sendo nosso intuito nesse capítulo tornar bem patente ao julgamento de todo o elevado grau de perversidade que preside sempre ao infanticídio, a grande depressão moral que afeta a mulher que o pratica." ${ }^{36}$

Observa-se, portanto, uma perspectiva de adoecimento da criminosa. Em algumas teses, os médicos consideram as mulheres que cometem aborto. ou infanticídio tipos femininos especiais. Mas o que se torna mais presente, enquanto corrente de pensamento, e mais aceito pela maioria dos médicos, é a idéia de que a mulher que chega a cometer esses crimes não é muito diferente das demais, sendo apenas o resultado da constituição feminina degenerada. Todas as mulheres têm uma só base constitucional, frágil e selvagem, que pode levar a esse tipo de atrocidade; o ódio materno que pode levar ao assassinato de um filho não é uma situação especial: é o șinal de uma falta de moralidade presente em todos os indivíduos do sexo feminino.

36. MILITÃo PACHECO A., Do infantidio. Tese apresentada à Faculdade de Medicina do Rio de Janciro, 1892, p. 13. 
"Aparecem porém alguns casos não de amor, mas de ódio materno que são apresentados como objeção. É um engano. Nem são exceções nem contrariam observaçōes anteriores. ${ }^{-37}$

A partir dessas constatações, o tratamento dado a essas mulheres torna-se muito mais rígido, e as explicações dadas a esse comportamento refletem o movimento para situá-las em uma categoria patológica. As causas determinantes desses atos são consideradas ligadas a uma degradação do contingente feminino que, preocupado egoisticamente com seus próprios interesses, sem uma moral bem constituida que permita voltar-se para interesses sociais, dá vazão a seus instintos animais, não hesitando em livrar-se de qualquer empecilho que ameace o seu bemestar; é a mulher casada que engravida na ausência do marido; a mulher freqüentadora de acontecimentos sociais que não quer aparecer grávida; a mulher de vida fácil, perturbada no exercício de sua profissão por uma gestação inoportuna; a amásia que se vê surpreendida; a mulher de menores recursos, cujo orçamento seria desequilibrado pela vinda de uma criança. Essas mulheres que, sucumbindo às suas fraquezas, matam os próprios filhos são consideradas seres despreziveis, dignos dos piores castigos, numa clara tentativa de atemorização e demonstração de que a fragilidade feminina tem que ser contida. Os médicos discutem o tratamento dado às mulheres pelas leis penais. Se alguns mais exaltados pedem a pena máxima $\mathrm{e}$ lamentam a não-existência da pena de morte, a maioria procura tornar as penas mais pesadas e abolir as atenuantes existentes, tornando-as fatores agravantes.

"Quando a própria mãe for a autora do assassinato, será punida com penas mais brandas. Mas, perguntamos nós, quando uma mãe for tão perversa que mate o fruto de suas próprias entranhas, não recuando muitas vezes diante dos meios os mais violentos, não deveria constituir esse fato uma circunstância das mais agravantes?"*38

A defesa da honra, também não pode ser admitida como atenuante de um crime, pois uma mulher que engravida fora do casamento, mantendo relações ilícitas, já é uma mulher sem honra. Ela comete um duplo crime -adultério e infanticídio-, existindo portanto duas provas de sua depravação moral. Em vez de um afrouxamento, isso exige maior rigor das leis penais, através de um aumento de sua pena.

"Se a mulher procurou se ver livre do seu filho para ocultar a desonra é este um argumento contraproducente, não tem razão de ser, visto que essa mulher não tem

37. CASTROL T.L., op. cit., p. 141.

38. BARCELOS J.F., Do infanticídio. Tese apresentada à Faculdade de Medicina do Rio de Janciru, 1892, p. 13. 
honra alguma, nem coisa que dela se aproxime, pois que já ela não a possuía quando entreteve relação que não podia ter. ${ }^{.39}$

Tratando o comportamento dessas mulheres como uma patologia moral, partindo de grandes crimes para demonstrar o tipo de monstruosidade de que pode ser capaz uma mulher, a medicina abre espaço para um tipo de discurso no qual essa mulher, que sucumbe a suas bases degeneradas, é tratada como exemplo do perigo virtual da condição feminina. Baseando-se nisso, diz que todo e qualquer comportamento feminino que extravase ou não corresponda ao ideal de esposa e mãe é um símbolo da patologia feminina.

"A mulher original que se torna proeminente pela sua extraordinária devassidão, pelo grande desejo de jogar, pelo gosto infrene de pintar, escrever, viajar etc é capaz de matar seu próprio filho." 40

Toda mulher que abandona seus sagrados deveres familiares ou que não os cumpre adequadamente, de acordo com o modelo médico, é considerada uma criminosa em potencial, cuja selvageria superou os preceitos morais e humanos. Criminalizando a figura feminina, a medicina tenta contribuir para uma estratégia de garantir a permanência da mulher nos papéis sociais que the são determinados.

\section{2 - A prostituta}

A questão da prostituta também sofre algumas modificações a partir do final do século. Considerado de grande importância, pelo perigo que representa para a sociedade, por suas funestas conseqüências físicas e morais, o fenômeno da prostituição é significativo nos discursos médicos. O estudo de suas causas e conseqüências se aprofunda, os projetos de regulação se ampliam e, ao mesmo tempo, a tentativa de analisar o tipo de mulher que constitui essa camada feminina ganha novos contornos.

Em primeiro lugar, os médicos são unânimes em falar do crescimento desenfreado da prostituição, principalmente no Rio de Janeiro. Como causas desse fenômeno citam-se alguns fatos: a vinda de homens e mulheres de vida mais licenciosa de outros países; a escravatura, que mantinha mulheres em situação de vida pública clandestina, ou por necessidade de sobrevivência ou por serem obrigadas por seus senhores; a existência de bailes, teatros semilicenciosos e casas de jogos que propiciavam toda sorte de libertinagens. É claro que essa situação

39. MILITÃO PACHECO A., op. cit., p. 11.

40. Idem, p. 14. 


\section{MAPA ClASSIFICATIVO DA PROSTITUIÇAO DA CIDADE DO RIO DE JANEIRO ${ }^{41}$}

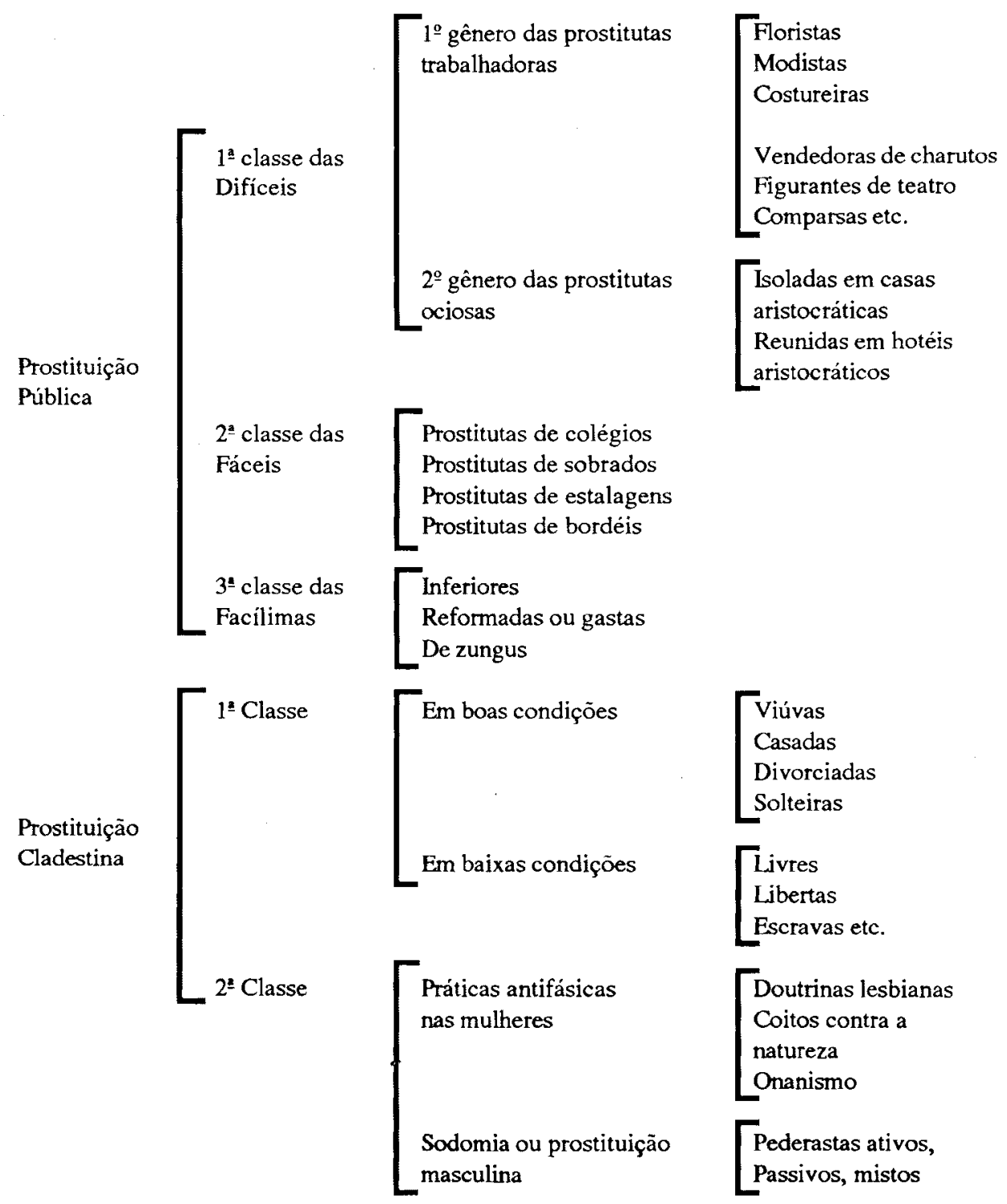

41. FERRAZ DE MACEDO F., De prostituição em geral e em particular da cidade do Rio de Janeiro: profilaxia da sifilis. Tese apresentada à Faculdade de Medicina do Rio de Janeiro. 1872 , p. 74. 
alarmante tornava imperiosa, aos olhos da medicina, uma ação reguladora e normativa dessas práticas, com vistas a combater as possibilidades de degradação social que poderiam sobrevir a um estado de coisas tão calamitoso. Para se realizar esse projeto, procede-se a um estudo minucioso das diferentes formas de prostituição, bastante mais abrangente do que aqueles apresentados na primeira metade do século. É surpreendente o grau de minúcia a que chega essa análise, que vai desde a "meretriz de salão" até a "prostituição masculina" e às "práticas masturbatórias", como se pode observar no quadro apresentado em uma dessas teses.

$\mathrm{O}$ aprimoramento dessa classificação demonstra a grande necessidade de catalogar e regular toda e qualquer forma de atividade sexual fora do laço conjugal. Ao mesmo tempo, as diferentes práticas sexuais passam também a ser assimiladas a práticas libertinas, que devem merecer um tratamento especial. Outro aspecto importante desse quadro é quanto ao tipo de mulher que procura essas atividades, que pertencem às mais diferentes origens: moças brancas ou negras, livres ou escravas, artistas, estrangeiras, jovens ou idosas, casadas ou solteiras, ricas ou pobres. As razões sociais que fazem com que essas mulheres, de diferentes inserções sociais, se voltem para a prostituição são analisadas cuidadosamente, assim como suas práticas licenciosas, sua influência sobre a sociedade, suas características mentais, crenças, vícios e virtudes. Tenta-se descrever todos os seus passos, abrangendo a totalidade de seu cotidiano, sua forma de vida, local de trabalho, hábitos e costumes. Mas, apesar das especificidades e das diferentes medidas que essa pluralidade de formas de prostituição pode demandar, no que concerne à questão da causa, mais importante se coloca o problema da desagregação social, de uma civilização imperfeita que leva as mulheres a um comportamento degradado. Os discursos médicos não defendem mais a idéia de que essas mulheres constituam um tipo feminino especial ou possuam uma constituição anormal, completamente antagônica ao tipo feminino geral; negativo da mãe, a prostituta não é mais o negativo do feminino. O que se pretende mostrar é que toda e qualquer mulher, dependendo de condições objetivas mais ou menos propícias, pode se voltar para a prostituição, já que sua condição pouco desenvolvida permite que, em algumas circunstâncias, elas degenerem de vez.

“As moças brasileiras, especialmente as filhas do Rio de Janeiro, quase todas franzinas, débeis, delicadas, são de uma susceptibilidade nervosa que espanta(...) Dai se chega facilmente à possibilidade de as flagelar uma ninfomania cujas consequências são das mais tristes e dignas de compaixão."42

42. Idem, p. 129 . 
É a susceptibilidade constitucional da mulher que pode levá-la à degradação e ao vício. O caráter da prostituta é idêntico ao das demais. A diferença é que aqueles sucumbem à sua estrutura deficiente. Elas não são exceção, mas confirmação da regra; não são variante, mas consequência. A prostituição é o resultado de fatores ambientais nocivos sobre a constituição primitiva da mulher.

As propostas médicas para controle desse fenômeno são mais ou menos as mesmas do primeiro momento: circunscrevê-las num determinado local, submetêlas a vigilância sanitária e policial e aplicar sobre elas uma legislação reguladora. Este tripé que possibilita disciplinar a prática da prostituição.

\section{3 - A loucura feminina}

O problema da loucura e da alienação constitui, dentro da medicina higiênica, um capitulo fundamental. Como dissemos anteriormente a questão da higiene social só aparece com o desenvolvimento da psiquiatria e a valorização da noção de degeneração psíquica. Esta noção abre espaço para se falar de indivíduos portadores de uma constituição mórbida. A loucura e a alienação mental são então consideradas uma conseqüência dessa degeneração psíquica que existe sempre nesses indivíduos. Antes, uma pessoa poderia ter episódios de loucura e remissões que a tornassem novamente lúcida. Agora, uma vez louca, sempre louca. A loucura é uma comprovação da existência da degeneração. As características constitucionais do louco são as características do degenerado. Elas resultam de deficiências orgânicas hereditárias que, em determinadas circunstâncias, levam ao fenômeno patológico.

"A causa que domina o desenvolvimento das afeç̧ões mentais, a causa das causas é a degeneração orgânica, hereditária, congênita ou adquirida, permanente ou momentânea e que se traduz por uma susceptibilidade especial do sistema nervoso. Essa suscetibilidade se manifesta sob a influência de causas externas que facilmente atuam e que são inerentes ao meio em que vive o individuo predisposto. ${ }^{.43}$

Ora, se para a loucura ocorrer é preciso que haja predisposição mórbida de um organismo que já carrega estigmas degenerativos, é claro que um organismo como o da mulher, cheio de deficiências, estará mais sujeito a essa afecção do que o organismo do homem. Os estudos das afecções mentais na mulher tentam demonstrar o fato de que a mulher está mais próxima do louco.

43. AVELAR ANDRADE L.C.,Responsabilidades legais das histéricas. Tese apresentada à raculdade de Miedielna do Rlo de Janeiro, 1888, p. 86. 
"A hereditariedade da loucura, porém, afeta mais os indivíduos do sexo feminino(...) esse fato é de fácil explicação em vista da idiossincrasia moral da mulher, que a expõe mais do que o homem às diversas lesões nervosas." ${ }^{44}$

Ao mesmo tempo, as teorias psiquiátricas dizem que a degeneração psíquica é consequência, também, de uma civilização defeituosa, que não possibilita um bom amadurecimento do organismo do indivíduo. Ora, se a degeneração pode produzir a loucura, por via de conseqüência uma civilização errônea leva a esse estado. Este também é considerado um fator que aumenta a possibilidade de a mulher adoecer, já que ela, por causa de um processo civilizatório rudimentar que a deixa próxima a seres inferiores, fica ainda mais próxima do louco. Para comprovar e melhor estudar a maior predisposição mórbida do sexo feminino para a loucura e as neuroses em geral, dois assuntos são privilegiados: loucura puerperal e histeria.

A loucura puerperal, um tipo de loucura que se desenvolve durante o período que se estende do momento da concepção até o momento da extinção do fluxo lácteo, abre espaço para que se aprofunde a questão da mulher que adoece. $O$ sexo feminino, que normalmente já possui uma estrutura prestes a desintegrar-se, na gravidez, quando está carregando dentro de si um novo indivíduo, deve merecer ainda mais atenção. Quando enlouquece, uma mulher grávida oferece maior perigo para a regeneração social, já que pode colaborar para aumentar degeneração da população, por estar em ligação direta com uma criança. A existência desse tipo de afecção ganha, por isso, grande relevância no pensamento médico. Seu estudo vai retomar a problemática da constituição feminina. Antes pensada como uma afecção diretamente ligada ao estado gravídico e ao parto, a loucura puerperal é agora vista como um fenômeno que depende da organização física e mental da mulher. Se esse estado propicia o surgimento da doença, é uma demonstração de que todo cuidado deve ser tomado durante esse período. Qualquer estímulo maior, qualquer mudança na vida da mulher pode propiciar a eclosão do quadro clínico. Logo, se a mulher normalmente deve ser cercada de todos os cuidados, quando em fase de procriação deve ter esses cuidados redobrados. Para evitar essas conseqüências mórbidas, a mulher grávida deve ser resguardada de todo contato com o mundo, de modo a não alterar seu já precário equilíbrio.

"As pancadas, as quedàs, bem como os desgostos e todas as paixões violentas e deprimentes deverão ser cuidadosamente observados." ${ }^{45}$

44. RODRIGUES OLIVEIRA O.S., Loucura puerperal. Tese apresentada à Faculdade de Medicina do Rio de Janeiro, 1882 , p. 10.

45. Idom, p. 66. 
Todo cuidado é pouco para prevenir que aquela que forma a criança e a acompanha na primeira infância não funcione como um agente de contaminação e degeneração da espécie. Como as causas que podem levar ao adoecimento são as mais variadas, indo desde fatores físicos a emocionais e morais, passando por traumatismo e qualquer tipo de excessos do cotidiano, o programa de normas que a mulher deve seguir, para evitar esse mal, funciona de forma a restringir a totalidade de sua vida.

Em relação à histeria o interesse não é menor. Embora esta afecção não esteja diretamente ligada à procriação, a partir do final do século ela é freqüentemente discutida e considerada um modelo privilegiado de degeneração feminina. Os trabalhos sobre histeria procuram basicamente demonstrar que ela está ligada ao fenômeno da degeneração e criticam violentamente qualquer teoria que pretenda estabelecer outra concepção sobre as suas causas. Combatem-se idéias correntes de que a histeria teria a ver com uma disfunção de órgãos genitais femininos, tais como problemas uterinos ou mesmo continência sexual. A questão da histeria não seria um problema localizado, e sim ligado à constituição dos doentes: aproxima-se, na verdade, de outros fenômenos ligados à degeneração, como por exemplo a criminalidade.

"Sob o ponto de vista fisiológico, o criminoso seria notável por um enfraquecimento da sensibilidade podendo afetar várias formas. De fato sua sensibilidade afetiva é nula ou pervertida. Como as histéricas são instáveis, vaidosas, dadas à vingança e à crueldade, inclinadas a orgias de todas as espécies, um dos caracteres mais constantes é a preguiça ou a incapacidade de aplicações para um trabalho regular. ${ }^{46}$

Ora, se a histérica apresenta características similares às do criminoso, e se este tem um tipo de enfraquecimento ou perversão observável nos indivíduos degenerados, deduz-se que a histérica é uma degenerada psíquica. Esse fato marca definitivamente a idéia de que a histeria é basicamente uma doença feminina. De maneira geral, as teses falam da histeria como um apanágio da mulher: raramente se vê uma referência a $u m$ histérico; ao contrário, os trabalhos sobre o tema se referem ao portador da doença como $a$ histérica. Encontramos, por exemplo, trabalhos que pretendem estudar a doença como um todo com seu título no feminino - "A responsabilidade legal das histéricas" ou "O delírio nas histéricas" -, ou então descrições de características clínicas da doença cujo sujeito também está no feminino.

to. AVELAR AINDRADE L.C., op. cit., p. 64 
“As histéricas são raparigas de uma grande vivacidade intelectual, precoces em excesso, com uma fisionomia expressiva, impressionáveis, coquetes, procurando fixar sobre si a atenção de todos os presentes." ${ }^{47}$

Ao mesmo tempo, vários desses trabalhos apresentam estatísticas que demonstram como a histeria atinge preferencialmente as mulheres.

“Já é conhecido, segundo afirmaremos adiante e por todos sabido, que a histeria é mais freqüente na mulher que no homem, segundo a nossa estatística apresentamos 678 casos de ataque histérico, pertencendo ao sexo masculino apenas 72 e ao sexo feminino os demais que são 606 , número incontestavelmente maior. Isso quer dizer que aos homens tocam apenas $8 \% . " 48$

A justificativa médica para o fenômeno de a doença ser muito mais freqüente na mulher é a estrutura física e mental desta. A histeria, como as demais formas de degeneração psíquica, resulta de um problema hereditário e de adaptação. Um organismo débil e uma intervenção ou parada no desenvolvimento constituem suas causas principais.

"De fato todas as causas da histeria podem se resumir nos dois fatores: hereditariedade e adaptação." 49

Ora, a mulher, pela sua própria história, é alguém que não sofreu adaptação adequada e teve suas características frágeis tomadas hereditárias. Logo, por sua própria fisiologia, ela se encontra mais exposta à doença. Daí a maior freqüência de casos de histeria no sexo feminino.

"Ora, a característica da histeria sob o ponto de vista etiológico é a paralisia cerebral e a hipercinesia medular(...) A grande freqüência na mulher de uma moléstia que se caracteriza pela inibição cerebral explica-se pela condição anatomofisiológica."so

A questão da histeria ocupa um lugar privilegiado nos discursos médicos, já que pode favorecer dois movimentos táticos da medicina: reforça a idéia de que as

47. PAULA L., O delírio nas histéricas. Tese apresentada à Faculdade de Medicina do Rio de Janeiro, 1889 , p. 4.

48. MULLER P., O pithiatismo. Tese apresentada à Faculdade de Medicina do Rio de Janeiro, 1886, p. 41.

49. FERNANDES FIGUEIRA A., Histeria. Tese apresentada à Faculdade de Medicina do Rio de Janeiro, 1886, p. 41.

Fo. CASTKO I.L., op. cit., p. 38. 
neuroses estão diretamente ligadas à problemática da degeneração dos indivíduos e demonstra, através da relação mulher-histeria, que o sexo feminino tem uma estrutura mais primitiva, já que é mais atingido por uma afeç̧ão com essas características. Dessa forma, se diz que -, apesar de não ser uma exclusividade feminina, o que colocaria em primeiro plano a questão do sexo, e não a da degeneração -, a histeria está mais presente nas mulheres, por fatores constitucionais. Mais ainda: todas as mulheres podem sucumbir a essa afecção.

Se a histeria resulta de uma falência no controle dos aspectos degenerados das mulheres, quando ela ocorre se torna um risco para a sociedade. Algumas alterações das histéricas podem constituir um perigo para a estratégia médica de regulação social. Entregues a seus instintos, elas não possuem limites para o seu desregramento, que pode contribuir grandemente para o caos social. Isso se observa, por exemplo, nas alterações que podem ocorrer em sua sexualidade.

"Quanto às perversões sexuais, à masturbação, à inversão do senso genital, o amor lésbico etc(...), são muito mais freqüentes nas histéricas cuja imaginação é desregrada e superexcitada, como em todos os degenerados; a necessidade do coito normal pode ser também patologicamente exagerada e vê-se então as raparigas ou mulheres casadas tornarem-se verdadeiras messalinas. ${ }^{-51}$

Podendo, portanto, por um transtorno na sexualidade, partir para comportamentos perversos, as histéricas ameaçam violentamente o ideal de esposa e mãe $\mathrm{e}$, conseqüentemente, a ordem social. Adultério e prostituição, com todo o seu cortejo de conseqüências funestas, são as ameaças maiores que recaem sobre essas mulheres.

"A história é o início de um caminho misterioso, triste e mau. Frequentemente ela é que conduz a mulher para um abismo: adultério ou prostituição." ${ }^{2}$

Uma proposta francamente preventivista em relação à histeria aparece no projeto da medicina. Baseados numa idéia de periculosidade virtual do contingente feminino, os médicos procuram localizar aquelas que podem adoecer mais facilmente. Partindo do estudo do caráter das histéricas, falam das particularidades femininas que podem levar a uma crise histérica. As mulheres portadoras de determinadas características passam a ser consideradas futuras doentes.

51. PAUla L., op. cit., p. 6.

52. MULLEK P., op. cil., p. 34. 
"Afirma Regis que principalmente no sexo feminino os futuros histéricos se fazem notar pelas características particulares. São na maioria dos casos moças de uma grande vivacidade intelectual, precoces em excesso, impressionáveis, coquetes, preocupando-se em especial em prender sobre si a atenção alheia, hábeis em mentir, sujeitas além disso aos terrores noturnos e aos pesadelos." ${ }^{53}$

Ai daquelas que, vivazes ou sujeitas a pesadelos, formam esse contingente que estaria predestinado a doenças; devem ser constantemente vigiadas, controladas, reeducadas, afastadas de qualquer fator que possa desencadear o quadro, ou de outros indivíduos que possam com ela se enfraquecer; a provável histérica se torna uma iminente ameaça social.

Esse tipo de discurso que descreve a mulher como um ser doentio, capaz de fazer mal a si e a toda sociedade, viabiliza a tentativa de torná-la cada vez mais incapacitada a gerir sua própria vida. Ao mesmo tempo, trata como patológico qualquer comportamento que não corresponda ao modelo de esposa e mãe. A mulher passa a ser tratada como alguém que deve estar permanentemente sob controle médico, que deve regular cada um de seus passos. No afã de controlar e prevenir toda a possibilidade de degeneração, os médicos propõem medidas de normalização, que vão desde um projeto de educação para a mulher até um esquadrinhamento minucioso de seu dia-a-dia. Um programa de educação e controle feminino, que deve funcionar como mecanismo de disciplinarização de seu corpo e de seu caráter, com vistas a adestrá-los o melhor possível para a vida em sociedade.

\section{RESUMO}

\section{A Medicina Social e a Questão Feminina}

Este trabalho pretende analisar o tipo de saber sobre a mulher produzido pela medicina a partir da constituição de uma medicina social, no século XIX, no Rio de Janeiro. Podemos observar a constituição de um discurso sobre o sexo feminino que, calcando-se na noção de degeneração psíquica, vai tratá-lo como possuidor de uma base degenerada, podendo portanto sucumbir às mais terriveis ameaças. Esse tipo de discurso que descreve a mulher como um ser doentio, capaz de fazer mal a si e a toda sociedade, viabiliza a tentativa de torná-la cada vez mais incapaz de gerir sua própria vida, tratando como patológico qualquer comportamento que não corresponda ao modelo de esposa e mãe.

53. COUTINHO DA SILVEIRA E.B., Haverá loucura histérica?. Tese apresentada à Faculdade de Medicina do Riu de Janeiro, 1918, p. 47. 
ABSTRACT

\section{Social Medicine and the Woman's Question}

The paper analyzes the kind of knowledge on women that has been produced by medical science since the formation of social medicine in Rio de Janeiro in the nineteenth century. We can observe the emergence of a discourse concerning the feminine sex - a discourse that rests on the notion of psychic degenerateness and that would come to view the female sex as possessing a degenerate base and thus as liable to succumb to the most terrible menaces. This type of discourse, which paints woman as an un wholesome being capable of harming herself and all society, would serve to ground the effort to make women ever more incapable of managing their own lives and to treat any behavior that fails to correspond to that of a model wife and mother as pathological.

\section{RESUME}

\section{La Medecine Sociale et la Question Feminine}

Ce travail a pour but d'analyser le type de savoir produit sur la femme par la médecine à partir de la constitution d'une médecine sociale, a Rio de Janeiro au XIXème siècle. On peut alors observer la formation de tout un discours concernant le sexe féminin où, à partir de la notion de dégénération psychique, ce sexe apparait comme fondamentalement dégénéré, capable de succomber aux plus terribles menaces. Ce type de discours, où la femme est décrite comme un être maladif, capable de porter préjudice à soimeme et à toute la société, va permettre le surgissement d'une tendance visant à la priver progressivement de tout pouvoir de gérer sa propre vie et va classer comme pathologique tout comportement échappant au modèle d'épouse et de mère. 